\title{
Una comparación randomizada entre inyección única y doble en el bloqueo costoclavicular guiado por ultrasonido
}

\author{
Layera S. ${ }^{1}$, Bravo D. ${ }^{1}$, Fernández D. ${ }^{1}$, Jara Á. ${ }^{1}$, Aliste J. ${ }^{1}$
}

1 Universidad de Chile, Santiago, Chile.

Introducción: El bloqueo costoclavicular con inyección única no ha demostrado diferencias respecto al abordaje infraclavicular convencional. Esto se explicaría por la distribución no homogénea del anestésico local luego de una inyección única entre los 3 cordones. Nuestra hipótesis es que una inyección doble en el espacio costoclavicular permitiría compensar este efecto, disminuyendo la latencia de bloqueo.

Métodos: Se reclutaron pacientes entre 18 a 75 años programados para cirugía de extremidad superior distal a codo bajo anestesia regional y sedación intravenosa. Se excluyeron sujetos con contraindicaciones para bloqueo de plexo braquial, dolor crónico y cirugía previa en región infraclavicular. Una vez obtenido el consentimiento, los pacientes fueron randomizados para recibir un bloqueo costoclavicular con inyección única, o bien una inyección doble, con $35 \mathrm{ml}$ de bupivacaína $0,25 \%$, lidocaína $1 \%$, epinefrina $5 \mathrm{mg} / \mathrm{ml}$ y dexametasona $2 \mathrm{mg}$. Posteriormente, un evaluador ciego a la randomización realizó una medición del bloqueo sensitivo-motor de los nervios terminales del plexo braquial cada 5 minutos hasta los 30 minutos post-bloqueo, determinando el tiempo de latencia hasta conseguir un bloqueo exitoso. Además de las variables demográficas, se registraron el tiempo de ejecución, dolor asociado al procedimiento, la incidencia de anestesia quirúrgica y ocurrencia de eventos adversos relacionados con el bloqueo.

Los datos fueron analizados con STATA 15.

Resultados: Durante un período de 2 meses se reclutaron 36 pacientes. No se registraron diferencias entre ambos grupos en cuanto a tiempo de ejecución, dolor procedimental, incidencia de eventos adversos o tasa de éxito de bloqueo quirúrgico. Comparado con una inyección única, la inyección doble no logró mostrar una diferencia en el tiempo de latencia $(19,6[5,5]$ vs 19,6 [6,9] minutos).

Conclusiones: En este reporte preliminar, la inyección doble en el bloqueo costoclavicular con $35 \mathrm{ml}$ de solución anestésica no disminuye el tiempo de latencia en comparación con la inyección única. Se requieren estudios adicionales utilizando menores volúmenes para evaluar si existen beneficios con la inyección doble en relación al tiempo de latencia o tasa de éxito.

https://doi.org/10.25237/congresoclasa2019.89 